\title{
Resistance to Fusarium Head Blight and Seedling Blight in Wheat Is Associated with Activation of a Cytochrome P450 Gene
}

\author{
X. Li, J. B. Zhang, B. Song, H. P. Li, H. Q. Xu, B. Qu, F. J. Dang, and Y. C. Liao
}

First, second, third, fourth, fifth, sixth, seventh, and eighth authors: Molecular Biotechnology Laboratory of Triticeae Crops, Huazhong Agricultural University, Wuhan 430070, P.R. China, and eighth author: College of Plant Science and Technology, Huazhong Agricultural University, Wuhan 430070, P.R. China. Accepted for publication 5 October 2009.

\begin{abstract}
Li, X., Zhang, J. B., Song, B., Li, H. P., Xu, H. Q., Qu, B., Dang, F. J., and Liao, Y. C. 2010. Resistance to Fusarium head blight and seedling blight in wheat is associated with activation of a cytochrome P450 gene. Phytopathology 100:183-191.

One plant genotype displays a resistance phenotype at one development stage but a susceptible reaction to the same pathogen at another stage, which is referred to here as resistance inversion. In wheat, Fusarium head blight (FHB)-resistant cv. Sumai3 showed a Fusarium seedling blight (FSB)-susceptible reaction whereas FHB-susceptible cv. Annong8455 exhibited FSB resistance when challenged with a Fusarium asiaticum strain that produces deoxynivalenol (DON). The resistance to FHB and FSB in wheat was closely associated with expression of a plant cytochrome P450 gene in response to FHB pathogens and mycotoxins. Quantitative real-time polymerase chain reaction analyses showed that expression of nine defense-related genes in spikes and seedlings was

plant cytochrome $\mathrm{P} 450$ gene, $C Y P 709 C 1$, was clearly associated with the resistance reaction in both seedling and spike. The FHB-resistant Sumai3 accumulated 7-fold more P450 transcripts than did the FHB-susceptible Annong8455, while 84-fold more $\mathrm{P} 450$ transcripts were accumulated in the FSB-resistant Annong8455 than the FSB-susceptible Sumai3. A Fusarium strain with a disrupted Tri5 gene, which is not able to produce the first enzyme essential for trichothecene mycotoxin biosynthesis, also induced more P450 transcripts in FHB- and FSB-resistant cultivars. The fungal activation of the P450 gene was more profound in the FSBresistant reaction than the FHB-resistant reaction relative to their susceptible counterparts. DON triggered a differential expression of the P450 gene with comparable patterns in spikes and seedlings in a resistancedependent manner. These results may provide a basis for dissecting mechanisms underlying FHB and FSB resistance reactions in wheat and revealing functions of the cytochrome $\mathrm{P} 450$ in plant detoxification and defense.
\end{abstract} induced by the fungal infection, in which a massive accumulation of a
Fusarium head blight (FHB) and Fusarium seedling blight (FSB), caused by Fusarium spp., are economically important diseases on wheat and other small grain cereal crops worldwide. Infection by Fusarium pathogens may result in huge losses of crop quantity and quality as a result of contamination by trichothecene mycotoxins that are detrimental to human and domestic animals (30). FHB in wheat takes place in the spike, with reddish, scabby spikes in which the disease symptom is easily visible and Fusarium mycotoxins are directly accumulated in grains. As for wheat FSB, infection by Fusarium pathogens can occur at germination stage throughout the succeeding seedling development, with less disease severity being visible. FSB can provide pathogens for the subsequent epidemics of FHB. The same species from the Fusarium graminearum clade or F. culmorum are capable of causing both FHB and FSB in wheat $(28,37)$. In China, FHB in wheat was first reported in 1936 and, since then, FHB epidemics have become more severe and frequent in the middle and lower regions of the Yangtze River and in Heilongjiang province in northeastern China, together with FSB (4). FHB in wheat and barley has reemerged as a serious threat to agriculture in North America and Europe since the middle of the 1990s

Corresponding author: Y. C. Liao; E-mail address: yucailiao@mail.hzau.edu.cn

X. Li and J. B. Zhang contributed equally to the work.

* The $\boldsymbol{e}$-Xtra logo stands for "electronic extra" and indicates that the online version contains generation and characterization of a mutant strain carrying a disrupted Tri5 gene. Figure 1 appears in color online.

doi:10.1094/PHYTO-100-2-0183

(C) 2010 The American Phytopathological Society
$(15,21,32,39)$. Investigation of both FHB and FSB resistance in wheat cultivars upon challenge with Fusarium pathogens and trichothecene mycotoxins would provide more insight into the mechanisms involved in the regulations of resistance to Fusarium spp. and help to develop new strategies for enhancing overall plant resistance to Fusarium spp.

Over recent decades, considerable effort has been made in China to breed FHB-resistant cultivars, and the Chinese wheat cv. Sumai3 has been widely recognized as the best FHB resistance germplasm available and used in various FHB resistance breeding programs $(8,25)$. Genetic and molecular analyses have identified several quantitative trait loci (QTLs) that are associated with FHB resistance, and they have been mapped on their corresponding positions on the genome of Sumai3. Those QTLs attributed to initial infection, fungal spreading, and mycotoxin accumulation were identified through floret inoculation in spikes (3). Functional genomics studies have indicated that a group of host genes were activated in FHB-resistant wheat spikes in response to deoxynivalenol (DON)-producing FHB pathogens (1). Several defenserelated genes such as actin-depolymerizing factor and chitinase were activated by the FHB pathogen $(6,11,22)$. Inoculation of the FHB-resistant cv. Ning7840 with the FHB pathogen induced an increased expression of a 14-3-3 protein and antioxidant proteins (42).

P450 cytochromes form the largest family of proteins that catalyze most of the oxidation steps in plant secondary metabolism. Compounds metabolized by $\mathrm{P} 450$ enzymes can act as stress signals in plant defense $(9,19,35)$ or exert a direct antifungal activity (36). Expression of plant P450 genes was induced by the stress hormone methyl jasmonate (MJ) and fungal pathogens 
$(10,11,34)$. One fungal elicitor-induced P450 enzyme from tobacco catalyzes two successive hydroxylations in the formation of the sesquiterpene capsidiol, which is the primary antimicrobial compound in tobacco (24). One P450 gene in potato was also identified as a molecular marker of resistance to fungal pathogen Phytophthora infestans (33). The induction of a large number of P450 genes in plants has allowed recruitment of new functions such as detoxification of exogenous molecules (18).

Several studies have been conducted to evaluate for FHB resistance in wheat. However, few studies have dealt with FSB. In this study, both FHB resistance and FSB resistance were investigated for two wheat cultivars, revealing a resistance inversion in which the same genotypes display distinctly inverse resistance reactions to Fusarium pathogens at different development stages. Wheat cv. Sumai3 showed FHB resistance in spikes and FSB susceptibility in seedlings, whereas FHB-susceptible wheat cv. Annong8455 had FSB resistance. Quantitative real-time polymerase chain reaction (qRT-PCR) analyses revealed a resistancedependent activation of a plant $\mathrm{P} 450$ gene in wheat in response to Fusarium pathogens or trichothecene mycotoxins. These results suggest the presence of a new resistance mechanism, resistance inversion, in wheat in response to Fusarium pathogens, and an important role played by plant cytochrome $\mathrm{P} 450$ genes in protecting plants against trichothecene mycotoxins.

\section{MATERIALS AND METHODS}

Plant, fungal, and bacterial materials. FHB-resistant wheat cv. Sumai3 and FHB-susceptible wheat cv. Annong8455, based on previous FHB resistance assays by inoculation of spikes, were used throughout this study (37). F. asiaticum (strain no. 5035) that is capable of producing DON $(23,41)$ was isolated from a scabby wheat spike in an FHB-epidemic region in China and used for inoculation. Strain 5035 was used for the generation of a mutant strain that carried a disrupted Tri5 gene, designated as Tri5-. The Tri5 gene encodes trichodiene synthase, the first enzyme that is involved in the biosynthesis of the trichothecene mycotoxins, including DON, in Fusarium pathogens. Disruption of the Tri5 gene in FHB pathogen causes no synthesis of DON and results in a reduced pathogenicity on wheat (5). A Tri5 ${ }^{-}$strain was used for inoculation to assay its potential for activating a plant cytochrome P450 gene on wheat FHB and FSB resistance compared with that of the wild-type $F$. asiaticum strain. The strains were cultured on potato dextrose agar (PDA) for regeneration and in potato dextrose broth (PDB) for mycelium growth. Macroconidia were produced in half-strength CM-cellulose-yeast extract broth (7). Agrobacterium tumefaciens EHA105 was grown at $28^{\circ} \mathrm{C}$ in yeast extract broth (YEB) (26) supplemented with rifampicin $(100 \mu \mathrm{g} / \mathrm{ml})$ and used for the transformation of $F$. asiaticum. Escherichia coli XL1-Blue was grown in Luria-Bertani medium at $37^{\circ} \mathrm{C}$ for propagation of plasmids (26).

Inoculation and mycotoxin treatment of wheat spikes. For single-floret inoculation, the macroconidia suspension of $F$. asiaticum no. 5035 and a mutant strain Tri5 $5^{-}$was adjusted to a concentration of $5 \times 10^{5}$ spores $/ \mathrm{ml}$. At mid-flowering time for each treatment, 20 spikes of each cultivar, 1 spike per plant, were inoculated with either a $10-\mu \mathrm{l}$ droplet of the conidia or $15 \mu \mathrm{l}$ of DON (1.5 mg/ml) (Sigma-Aldrich, St. Louis) in 0.2\% Tween 20, or $0.2 \%$ Tween 20 in water as mock inoculations. Spikes were injected by a pipette tip to the central floret of one middle spikelet (37). After inoculation, the plants were kept humid for 3 days and grown in the plastic house. The fungal spreading rates on the inoculated spikes were evaluated 21 days postinoculation (dpi). For each spike, the percentage of the infected spikelets spreading from the inoculated spikelet was determined.

Inoculation and mycotoxin treatment of wheat seedlings. For seedling inoculation, wheat seed were disinfected with $0.01 \%$ $\mathrm{HgCl}_{2}$ for $1 \mathrm{~min}$ followed by two rinses of sterile distilled water.
After incubation on moist filter papers (Whatman) at $20^{\circ} \mathrm{C}$ for 3 days, the top 2 to $3 \mathrm{~mm}$ of coleoptiles were cut off and the tipcut apices were covered with a $1-\mathrm{cm}^{2}$ piece of filter paper soaked in conidial suspension or a solution containing DON $(20 \mu \mathrm{g} / \mathrm{ml})$. For each strain and cultivar, 20 coleoptiles were inoculated and grown in a growth chamber $\left(25^{\circ} \mathrm{C}, 95 \%\right.$ relative humidity) under a 12-h photoperiod (37). The brown lesions of diseased stems were measured $7 \mathrm{dpi}$.

qRT-PCR. Wheat spikes and seedlings inoculated with $F$. asiaticum 5035 or water were harvested 3, 6, 12, 24, 48, and $72 \mathrm{~h}$ postinoculation (hpi), while wheat spikes and seedlings inoculated with a Tri5 ${ }^{-}$strain were harvested $72 \mathrm{hpi}$ and the spikes and seedlings treated with DON mycotoxin were harvested 24 hpi. Ten spikes (one inoculated spikelet from each spike) or seedlings (the whole seedlings) for each treatment were harvested and used for RNA isolation. Three replicates were performed.

Total plant RNA was isolated using Trizol reagent (29) and treated with RNase-free DNase I (Takara, Dalian, China), followed by reverse-transcription with Superscript III (Invitrogen) and an oligo- $\mathrm{dT}_{20}$ primer.

qRT-PCR reactions were carried out in a volume of $25 \mu \mathrm{l}$ containing Sybr Greeen I PCR Master Mix (Toyobo, Osaka, Japan), $10 \mathrm{pmol}$ each of forward and reverse gene-specific primers, and $10 \mu \mathrm{l}$ of cDNA (1:100 dilution) derived from the above-mentioned reverse transcriptions. Gene-specific primers were designed using Primer Premier5 software (Premier Biosoft International, Palo Alto, CA). PCR amplification was performed in an iQ5 Cycler (Bio-Rad) under the following conditions: $95^{\circ} \mathrm{C}$ for $4 \mathrm{~min}$, followed by 40 cycles of $94{ }^{\circ} \mathrm{C}$ for $15 \mathrm{~s}, 62^{\circ} \mathrm{C}$ for $20 \mathrm{~s}$, and $72^{\circ} \mathrm{C}$ for $20 \mathrm{~s}$. The plate read was at $72^{\circ} \mathrm{C}$ for $30 \mathrm{~s}$. A melting curve was also performed to determine the specificity of each PCR primer by incubating the reaction at $95^{\circ} \mathrm{C}$ for $20 \mathrm{~s}$, cooling to $55^{\circ} \mathrm{C}$ for $10 \mathrm{~s}$, and increasing to $95^{\circ} \mathrm{C}$ at a rate of $0.5^{\circ} \mathrm{C}$ per $10 \mathrm{~s}$.

To normalize the total amounts of cDNAs present in each reaction and to eliminate the differences among the samples, a wheat $\beta$-actin housekeeping gene was co-amplified as an internal control. Each sample was replicated three times, and the $2^{-\Delta \Delta C T}$ method of relative gene quantification (13) was used to calculate the expression level of Fusarium spp. inoculation or mycotoxin treatment relative to their controls. The National Center for Biotechnology Information accession numbers for all the genes screened for $F$. asiaticum were listed in Table 1. These defenserelated genes were selected because they were induced in wheat in response to FHB pathogens or other fungal pathogens.

Statistic analysis. Student's $t$ test was used to show significant differences between disease resistance and gene transcript abundance in Sumai3 and Annong8455 with Excel software (Microsoft, Redmond, CA).

\section{RESULTS}

Wheat resistance inversion between Sumai3 and Annong8455. The results of inoculation with $F$. asiaticum strain no. 5035 showed a distinctly different resistance reaction for the two wheat cultivars at the two stages. In spikes after single-floret inoculation, cv. Sumai3 displayed more resistance $(11.4 \%$ infected spikelets) compared with cv. Annong8455 (43.2\%) $21 \mathrm{dpi}$ (Fig. 1A) (i.e., FHB resistance) (37). In seedlings after coleoptile inoculation, however, Annong8455 exhibited more resistance (1.01 cm of lesion length) than Sumai3 $(2.47 \mathrm{~cm}) 7 \mathrm{dpi}$ (Fig. 1B), termed here as FSB resistance. Thus, a resistance inversion between FHB and FSB in wheat was apparently present.

Induction of wheat defense-related gene expression in seedling and spike in response to the FHB pathogen. Nine defense genes were then assayed for their expression patterns at different times after inoculation of wheat seedlings and spikes with $F$. asiaticum strain 5035 by qRT-PCR. The results indicated 
that all nine genes were induced but accumulated at varied levels upon fungal infection, indicating that a proper host defense response in the seedlings and spikes was triggered by the FHB pathogen.

Among the genes assayed, four genes accumulated more transcripts in the seedlings than in the spikes (Fig. 2). These included a class I chitinase (Chil) gene (Fig. 2A and B), a class VII chitinase (Chi2) gene (Fig. 2C and D), a peroxidase precursor (TaPERO) gene (Fig. 2E and F), and a pathogenesis-related (PR) protein $(P R 4)$ gene $(2 \mathrm{G}$ and $\mathrm{H})$. The two chitinase genes and a $P R 4$ gene were shown to have their transcripts with peaks much earlier in the seedlings than in the spikes. In the seedlings of Annong8455 that displayed FSB resistance, the $P R 4$ was rapidly induced $3 \mathrm{hpi}$, followed by a second peak of induction. A similar peak was only seen $12 \mathrm{hpi}$ in the seedlings of Sumai3 that had an FSB-susceptible reaction, and no second peak was visible.

There are also genes whose expression was induced to a higher level in the spikes than in the seedlings (Fig. 3). Expression of a proteinase inhibitor-related protein (Wris) gene and a glutathione S-transferase (GST) gene was more profound in the spikes than in the seedlings for Annong8455, with an earlier induction peak at 3 to 6 hpi. A comparable expression pattern in the seedlings and spikes was detected for a peroxidase (Pox2) gene (Fig. 4A and B) and a calreticulin (CRT) (Fig. 4C and 4D) gene in the two cultivars. Taken together, these results indicated that $F$. asiaticum fungus effectively infected wheat seedling and spike tissues and, accordingly, induced the expression of a set of host defenserelated genes, suggesting that the pathogenesis in wheat seedlings was apparently similar to that observed in spikes when challenged with FHB pathogens.

Association of wheat resistance with activation of a $\mathbf{P 4 5 0}$ gene. Expression of a plant cytochrome P450 gene, CYP709C1, displayed a more close association with the resistance reaction. Infection by the $F$. asiaticum strain 5035 induced a 464-fold increase of the P450 transcripts in the spikes of FHB-resistant Sumai 3 compared with the controls at 72 hpi, whereas a 66-fold increase of the transcripts was seen for the FHB-susceptible Annong8455 under the same conditions (Fig. 5A). In the seedlings through a similar comparison, however, a 15 - and 58-fold increase of the P450 transcripts were observed for the FSBresistant Annong8455 at 48 and 72 hpi, respectively, while, at the same times postinoculation, only a 2 - and 0.7 -fold increase were seen for the FSB-susceptible Sumai3 (Fig. 5B). Further analyses of transcript fold changes of the resistance reactions relative to susceptible counterparts showed that 7.1-fold more in spikes was seen for the FHB-resistant Sumai3 compared with the FHB- susceptible Annong8455, while 83.9-fold more in seedlings was found for the FSB-resistant Annong8455 compared with the FSBsusceptible Sumai3 (Table 2). Thus, the FHB resistance in spikes and FSB resistance in seedlings are closely associated with rapid and massive activation of a cytochrome P450 gene.

Activation of a $\mathbf{P 4 5 0}$ gene by a Tri5-disrupted Fusarium strain. Cytochrome P450 genes were involved in various reactions, including detoxification, and $C Y P 709 C 1$ was induced by strain 5035 that is a DON producer. To ascertain whether the expression of a P450 gene was regulated by trichothecene mycotoxins from the fungus, a mutant strain carrying a disrupted Tri5 gene, Tri5 ${ }^{-}$, was generated from Fusarium strain 5035. Molecular and chemical characterization confirmed that this strain contained a nonfunctional Tri5 gene and cannot produce DON. This Tri5 strain was used to inoculate wheat spikes and seedlings of the two cultivars to assay its induction potential of the P450 gene. The results clearly showed a differential activation of the $\mathrm{P} 450$ gene in wheat by the Tri5 ${ }^{-}$strain depending on resistance reactions. In spikes at 72 hpi, FHB-resistant Sumai3 accumulated a 15.3-fold increase of the P450 transcripts and a 10.1-fold increase was seen for FHB-susceptible Annong8455 compared with their mockinoculated controls (Fig. 5C; Table 2). In seedlings, however, FSB-resistant Annong8455 accumulated a 19.2-fold increase and FSB-susceptible Sumai3 only had a 0.9-fold change compared with their controls. Thus, the resistance reactions to the Tri5 $5^{-}$strain in wheat cultivars were also associated with more profound accumulation of the $\mathrm{P} 450$ transcripts.

By comparison, the Tri5- strain appeared to have a reduced capacity to activate the P450 gene, especially in FHB and FSB resistance reactions. For instance, 4.7-fold difference of the P450 transcripts was seen between the wild-type strain 5035 (7.1-fold, significant at $P<0.01)$ and the Tri5 ${ }^{-}$strain $(1.5$-fold, not significant) in spikes, whereas 3.7-fold variation was present between strain 5035 (83.9-fold, $P<0.01$ ) and the Tri5- strain (22.6-fold, $P<0.01$ ) in seedlings (Table 2). These results indicated that the differential activation of the P450 gene in wheat by FHB pathogens was apparently associated with the resistance complements in the hosts and DON mycotoxin in the pathogens.

Activation of a $\mathbf{P 4 5 0}$ gene by DON. The above results suggest that the presence or absence of DON during Fusarium sp. infection affects P450 gene expression. Subsequently, the role of DON alone in the activation of P450 gene was assayed in the two wheat cultivars $24 \mathrm{~h}$ after treatment. A massive increase of the P450 transcripts, up to 2,229-fold, was observed for the FHB-resistant Sumai3 and a 995-fold of P450 transcripts was induced for the FHB-susceptible Annong8455 in spikes relative to their mock-

TABLE 1. Primers and sequences used throughout this study

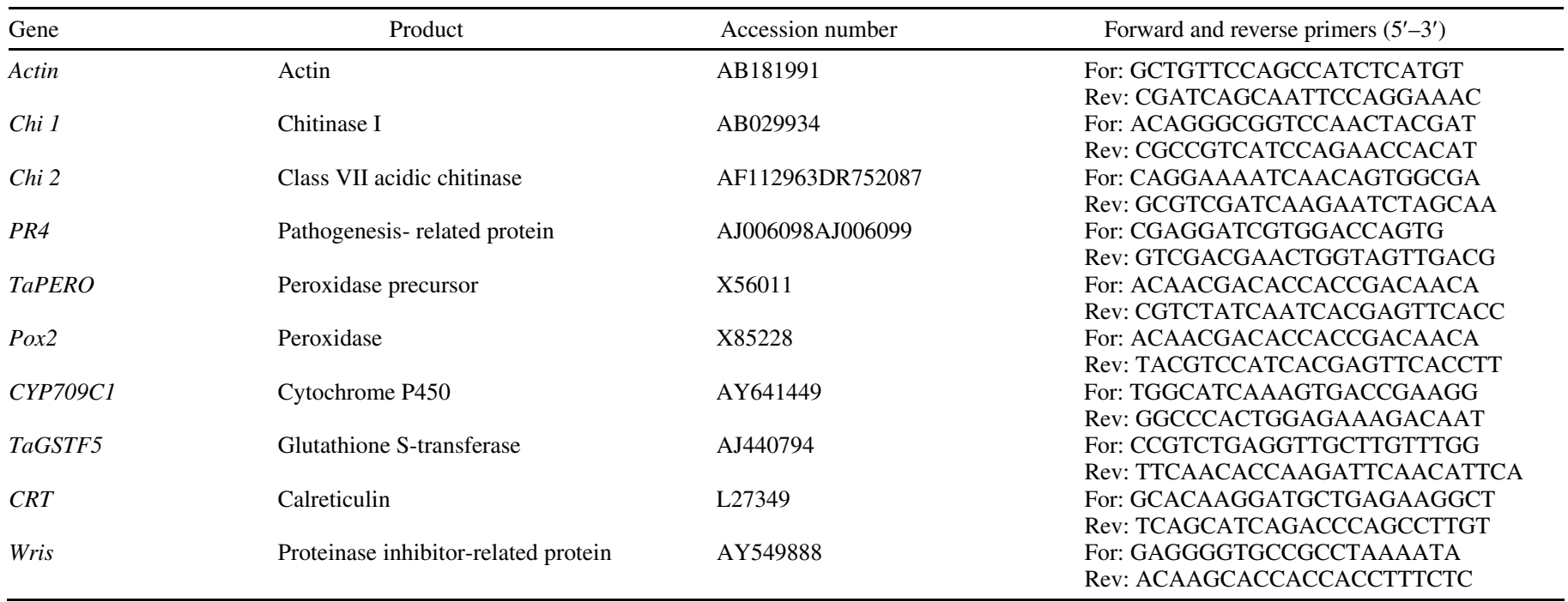


inoculated controls (Fig. 5D; Table 2). After treatment of wheat seedlings, the FSB-resistant Annong8455 accumulated 158-fold more P450 transcripts and 68-fold more transcripts were induced in the FSB-susceptible Sumai3 compared with their controls. Here again, the accumulation of the P450 transcripts induced by DON was clearly associated with the corresponding resistance reactions in wheat. The P450 transcript fold changes of wheat resistance to susceptibility were very similar in seedlings and spikes (Table 2). Thus, DON alone effectively activated a differential expression of the P450 gene in a resistance-dependent manner in seedlings and spikes of wheat.

\section{DISCUSSION}

Resistance inversion was used here to describe a resistance reaction in wheat in which one cultivar displayed FHB resistance in spikes but exhibited FSB susceptibility in seedlings, or vise versa. The present results show that these resistance reactions, either in seedlings or spikes, were closely associated with activated expression of a cytochrome $\mathrm{P} 450$ gene that was also regulated by DON. FHB-resistant cv. Sumai3 accumulated more P450 transcripts than did FHB-susceptible cv. Annong8455, whereas more P450 transcripts were induced in FSB-resistant cv. Annong8455 compared with that observed for FSB-susceptible cv. Sumai3 after inoculation with $F$. asiaticum or treatment with DON mycotoxin. This is the first report of a close association of resistance between FHB in spikes and FSB in seedlings in wheat with distinctly molecular profiles of defense-related gene expression, suggesting the presence of two resistance mechanisms evolved in wheat in response to FHB pathogens. Further investigation of signals and molecules underlying the resistance inversion would lead to more insight into the networks and mechanisms involved in the complex nature of overall wheat resistance to $\mathrm{FHB}$ pathogens.

$\mathrm{Wu}$ et al. (37) observed a consistent susceptible reaction at the seedling stage for three FHB-resistant wheat cultivars (Sumai3, Wangshuibai, and Fanshanxiaomai) and proposed an adult plant resistance (APR) for these cultivars, reminiscent of APR reported in resistance of rice to bacterial blight (16) and wheat to leaf rust $(2,27)$, stripe rust $(40)$, or powdery mildew (12). Different genes or QTLs were reported to be involved in FHB and FSB resistance in wheat $(31,38)$. FHB pathogens are necrotrophic fungal pathogens that are very much different from the obligate fungal pathogens in various aspects that display high specificity toward their hosts. The distinctly inverse resistance reactions at seedling and spike stages in wheat cultivars were closely associated with activation of the P450 gene. These results appear to suggest that wheat plants may have evolved a resistance mechanism similar to
A
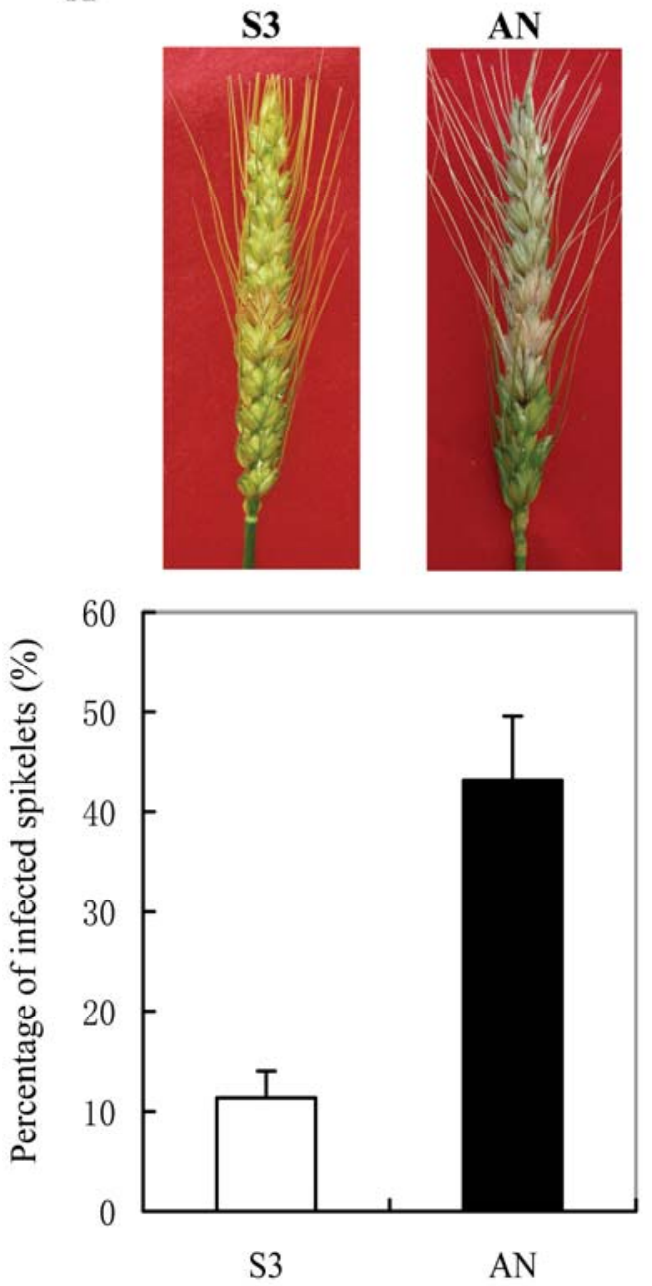

B
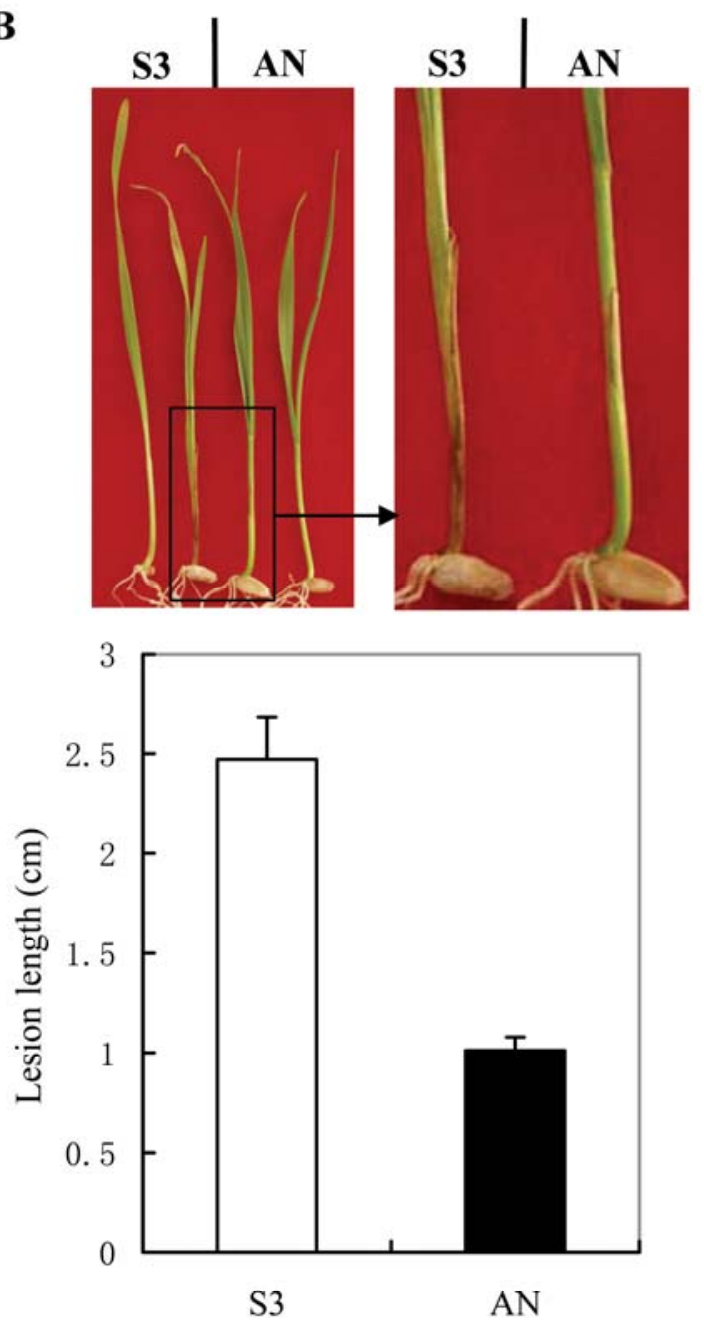

\section{Cultivar}

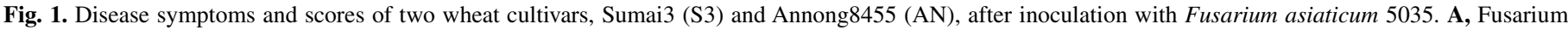

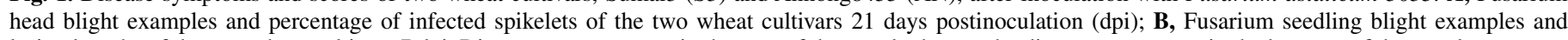
lesion lengths of the two wheat cultivars $7 \mathrm{dpi}$. Disease symptoms are in the tops of the panel whereas the diseases scores are in the bottoms of the panel. 
APR reported for obligate pathogens when challenged with nonspecific FHB pathogens.

In the current study, qRT-PCR analyses revealed that all nine defense genes were activated in wheat seedlings of both cultivars upon $F$. asiaticum inoculation, indicating that an effective Fusarium sp. infection triggered a general host defense response to a necrotrophic fungal pathogen. This gene activation apparently reflected an intimate interaction between the Fusarium pathogen and wheat tissues. The different induction patterns observed in this study may be due to the variations of genetic backgrounds of wheat cultivars that regulated the defense-related responses to fungal infection. Nevertheless, the current results from the defense-related gene induction in the seedlings and spikes by $\mathrm{Fu}$ sarium pathogens provided a basis for the dissection of molecular regulations and mechanisms of the different reactions in wheat seedlings and spikes as well as in cereal crops that Fusarium pathogens frequently infect in nature.

Rapid activation of a cytochrome $\mathrm{P} 450$ gene in a resistancedependent manner in wheat may suggest a specific, molecular interaction or recognition between the fungus infection and its host resistance. Significantly more P450 transcripts were accumulated in wheat plants with either an FHB or FSB resistance reaction compared with their susceptible counterparts. Based on these facts, fold changes of resistance relative to susceptibility were analyzed for the P450 gene expression (Table 2). The relative fold changes (resistant to susceptible) of the induced P450 transcripts between the wild-type Fusarium strain 5035 and the Tri5 ${ }^{-}$strain were comparable in seedlings and spikes. For instance, 4.7-fold change in spikes between strain 5035 (7.1-fold, relative to FHB-susceptible Annong8455) and the Tri5 ${ }^{-}$strain (1.5-fold, relative to FHB-susceptible Annong8455) was seen, whereas 3.7-fold difference in seedlings was present between strain 5035 (83.9-fold, relative to FSB-susceptible Sumai3) and the Tri5 $^{-}$strain (22.6-fold, relative to FSB-susceptible Sumai3) (Table 2). Strains 5035 and Tri5 ${ }^{-}$are isogenic and morphologically indistinguishable, including growth rate and macroconidia production. The later lost its Tri5 gene and was not capable of producing DON. It induced fewer P450 transcripts in seedlings and spikes compared with the wild-type strain 5035. This is in accordance with the previous reports that the Tri5strain had a reduced virulence toward wheat (5). However, the Tri $^{-}$strain still induced more transcripts of the P450 gene in the FHB-resistant Sumai3 (1.5-fold, relative to FHB-susceptible Annong8455) and, especially, in the FSB-resistant Annong8455
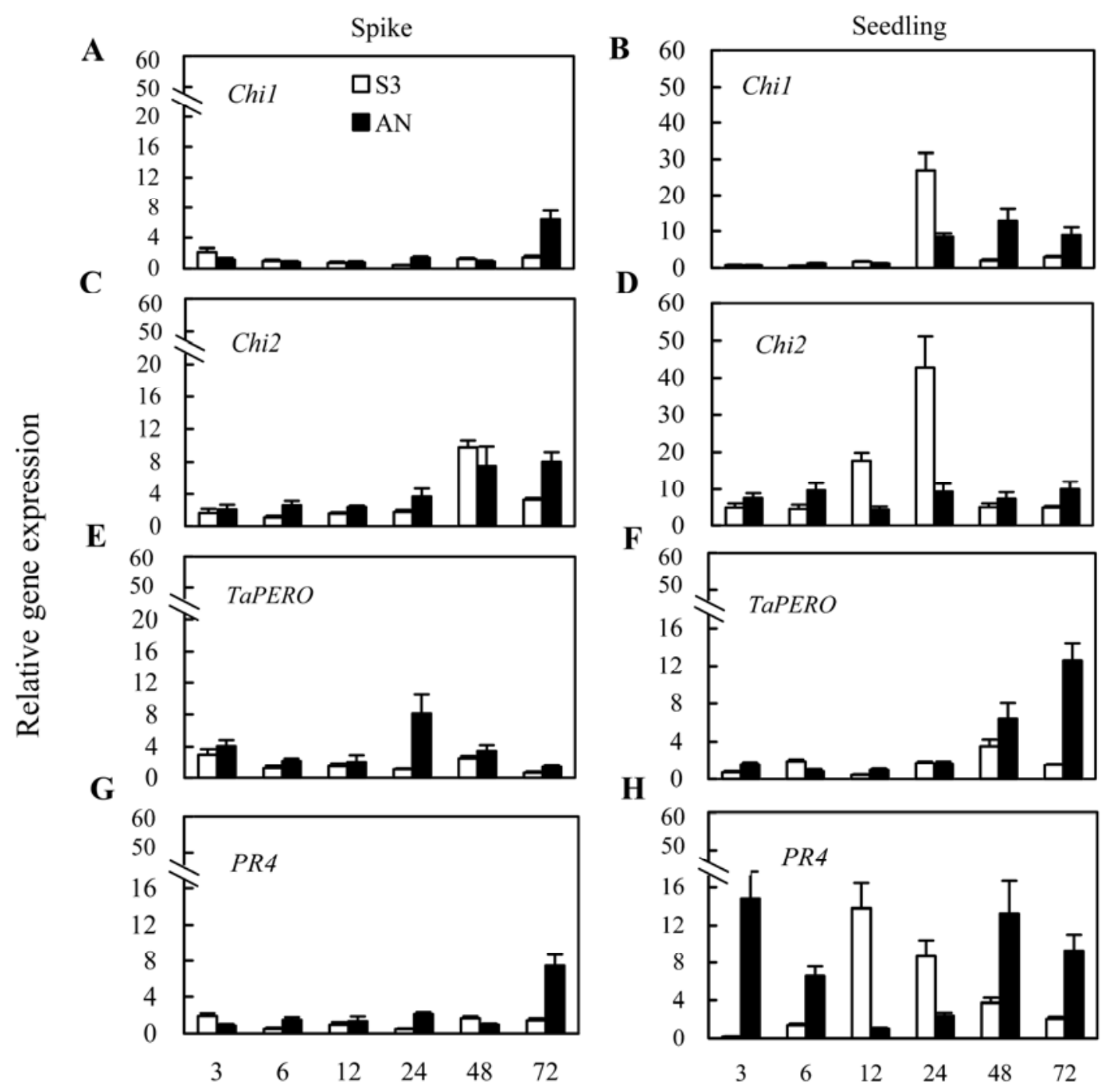

Hours after inoculation

Fig. 2. Quantitative real-time polymerase chain reaction analyses of defense-related gene transcripts with more accumulation in seedlings than in spikes of wheat after inoculation with Fusarium asiaticum 5035. Amounts of gene transcripts are calculated relative to mock-inoculations. A and $\mathbf{B}$, Chitinase I gene (Chil); C and $\mathbf{D}$, class VII acidic chitinase gene (Chi2); $\mathbf{E}$ and $\mathbf{F}$, peroxidase precursor gene (TaPERO); $\mathbf{G}$ and $\mathbf{H}$, pathogenesis-related (PR) protein gene (PR4). Spike gene transcripts are on the left and seedling gene transcripts are on the right. S3, Sumai3; AN, Annong8455. 
in seedlings (22.6-fold, relative to FSB-susceptible Sumai3), implying the presence of additional unknown virulence factors other than DON mycotoxin in FHB pathogens that interacted intimately with innate wheat resistance.

The activation of the P450 gene by DON alone (Fig. 5D) was closely associated with resistance inversion in spikes and seedlings of wheat. A similar resistance-dependent fold increase of the P450 transcripts after DON treatment in spikes (2.2-fold) and seedlings (2.3-fold) suggests that DON is an efficient plant resistance-responsive activator, interacting closely with molecules from wheat resistance reactions (Table 2). Furthermore, a comparable pattern of defense response in spikes and seedlings triggered by DON indicated that wheat cells from spikes and seedlings appear to perceive and transmit signals from DON at a similar rate and manner, although the cell compositions of wheat tissues might vary greatly at the two different development stages. DON was reported to act as a virulence factor on wheat spikes (5). The similar expression pattern of the P450 gene in seedlings and spikes upon DON treatment and Tri5- infection (Fig. 5; Table 2) suggests that DON also has a virulent role in seedlings. Investigation of genetic and molecular regulations of resistance reactions to trichothecene mycotoxins and mycotoxin-producing pathogens may eventually illustrate the role played by DON in the interaction or signal transduction in wheat.

This P450 gene belongs to a plant cytochrome gene subfamily, CYP709C1, and was the latest characterized P450 gene in plants.
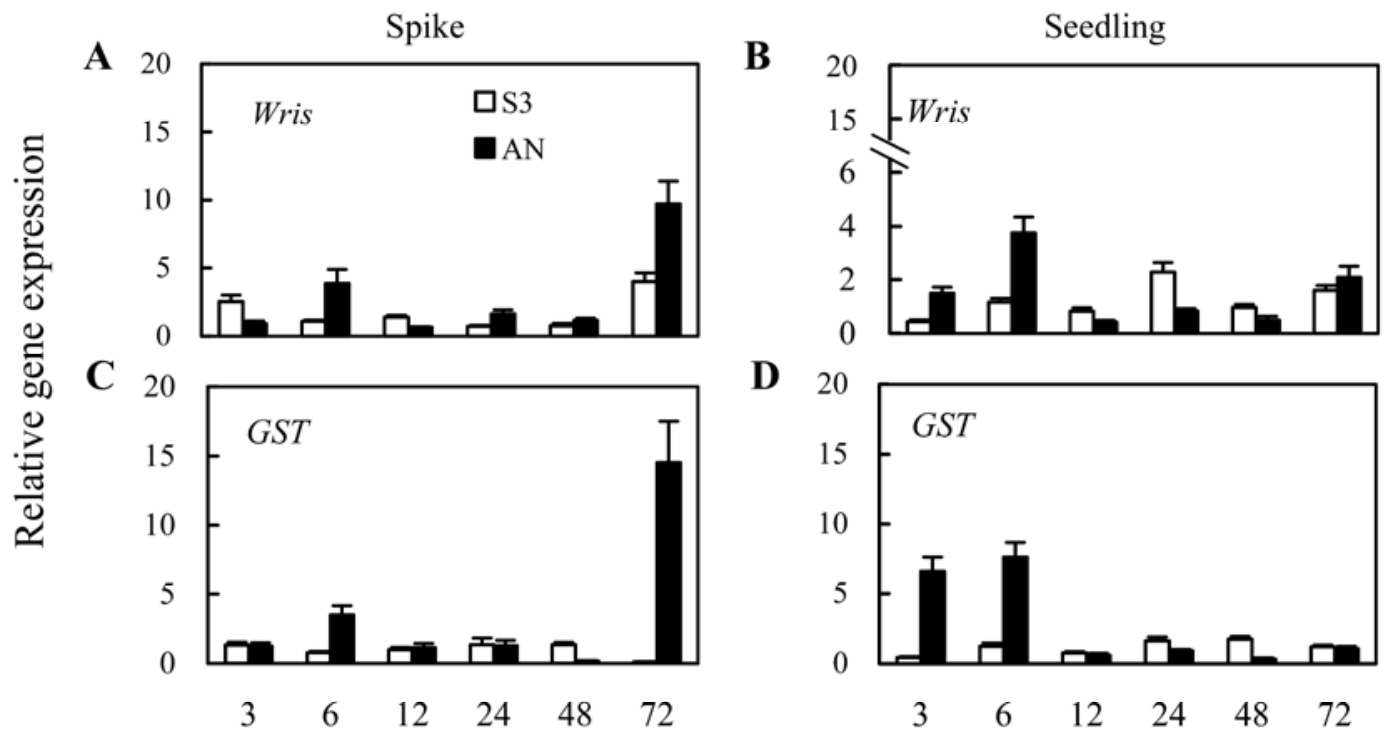

\section{Hours after inoculation}

Fig. 3. Quantitative real-time polymerase chain reaction analyses of defense-related gene transcripts with more accumulation in spikes than in seedlings of wheat after inoculation with Fusarium asiaticum 5035. Amounts of gene transcripts are calculated relative to mock inoculations. A and B, Proteinase inhibitor-related protein gene (Wris); C and D, glutathione S-transferase gene (GST). Spike gene transcripts are on the left and seedling gene transcripts are on the right. S3, Sumai3; AN, Annong8455.
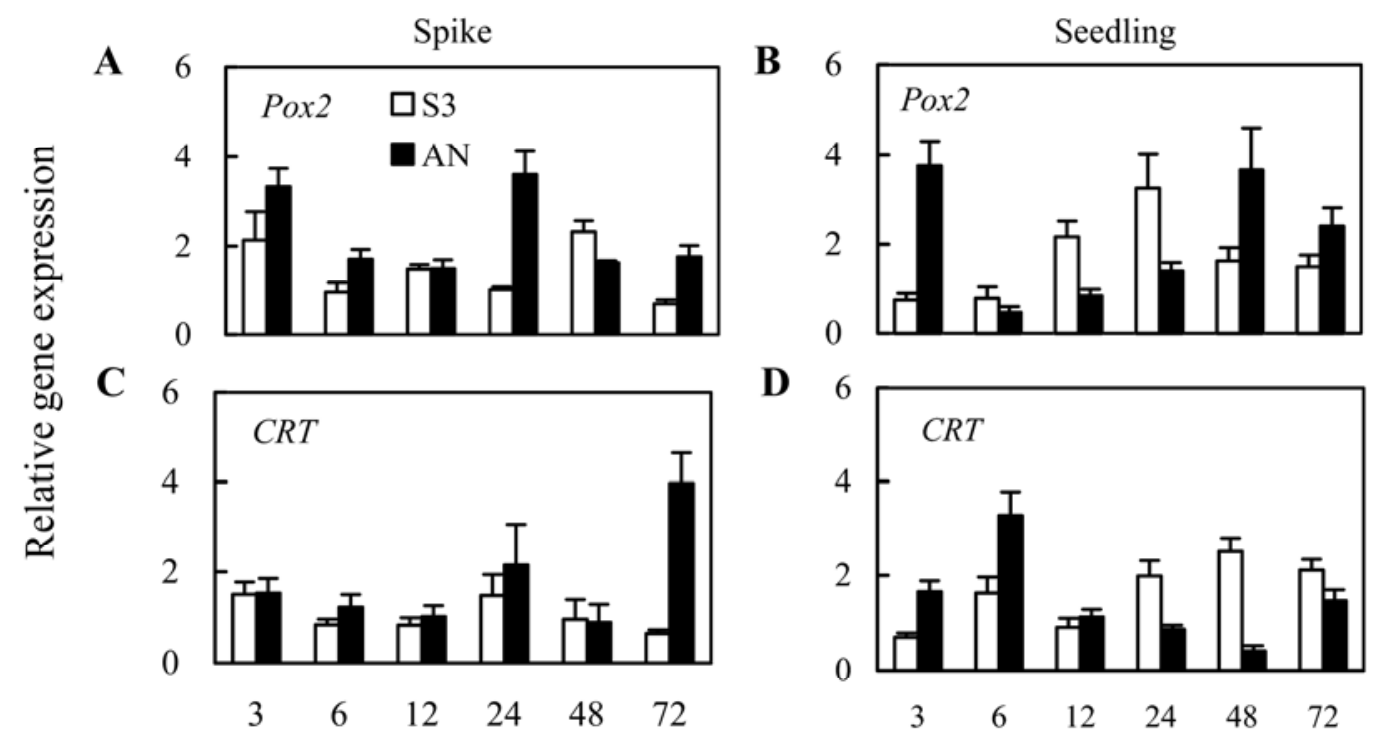

\section{Hours after inoculation}

Fig. 4. Quantitative real-time polymerase chain reaction analyses of defense-related gene transcripts with comparable accumulation levels in seedlings and spikes of wheat after inoculation with Fusarium asiaticum 5035. Amounts of gene transcripts are calculated relative to mock-inoculations. A and B, Peroxidase gene (Pox2); $\mathbf{C}$ and D, calreticulin gene (CRT). Spike gene transcripts are on the left and seedling gene transcripts are on the right. S3, Sumai3; AN, Annong8455. 
Plant cytochrome P450 genes have a diverse role in plant development and defense (18). It was induced in wheat by MJ and catalyzed C18 fatty acids by subterminal hydroxylation (10). Studies in animal P450 genes have been advanced, revealing an important role in detoxification (17) and, thus, a similar function has been proposed for plant P450 genes $(14,20,43)$. The functions of most plant P450 genes remain unclear and the role of the P450 gene in detoxification and signal transduction in the FHB and FSB resistance inversion in wheat still awaits further investigation. The consistent resistance-dependent induction patterns of the cytochrome P450 CYP709C1 shown in this study suggest an active involvement of the wheat cytochrome $\mathrm{P} 450$ gene in resistance response to FHB pathogens and DON. This implies that the system of wheat and FHB pathogens might be a suitable system for revealing molecular interactions between wheat cytochrome $\mathrm{P} 450$ and Fusarium mycotoxins.

More P450 transcript fold changes of resistance to susceptibility were observed in the seedlings after inoculation with strain 5035 (83.9-fold) and strain Tri5- (22.6-fold) (Table 2), indicating that wheat seedling tissues with an FSB resistance reaction responded more rapidly to stress stimuli such as fungal infection and thus, these tissues appear to be suitable host tissues for
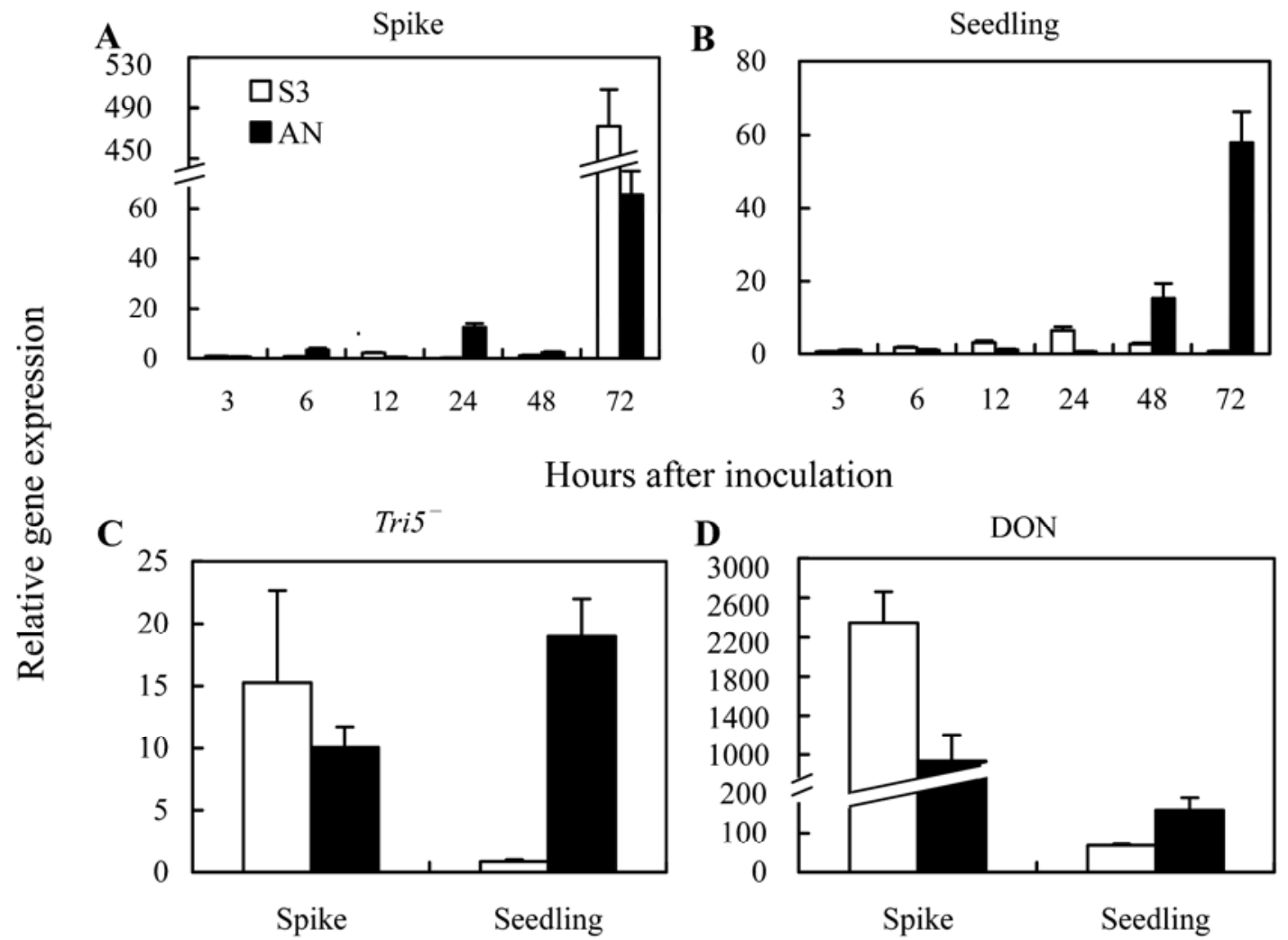

Fig. 5. Quantitative real-time polymerase chain reaction analyses of cytochrome $P 450$ gene transcripts in spikes and seedlings of wheat after inoculation with Fusarium asiaticum or treatment with mycotoxins. A and B, Transcripts in spikes and seedlings, respectively, after inoculation with a $F$. asiaticum strain 5035; C, transcripts in spikes and seedlings $72 \mathrm{~h}$ postinoculation with a Tri5 ${ }^{-}$strain; D, transcripts in spikes and seedlings $24 \mathrm{~h}$ after treatment with deoxynivalenol (DON). Amounts of the gene transcripts are calculated relative to mock inoculations. S3, Sumai3; AN, Annong8455.

TABLE 2. Transcripts and fold changes of a plant cytochrome P450 gene associated with resistance inversion between Fusarium head blight and Fusarium seedling blight in two wheat cultivars (Sumai3 and Annong8455) ${ }^{\mathrm{a}}$

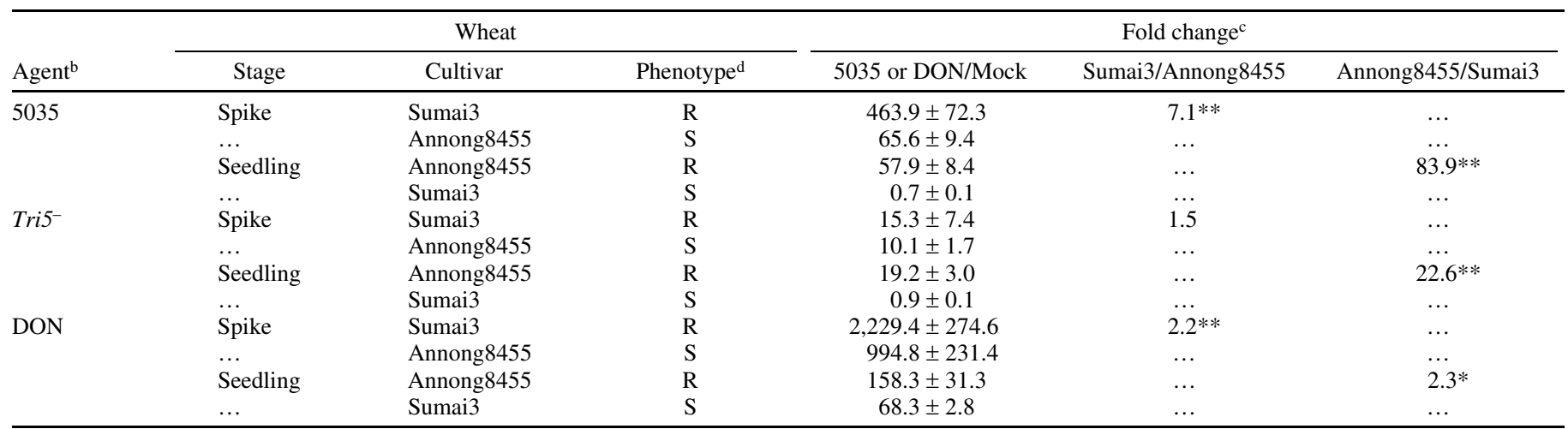

\footnotetext{
${ }^{a}$ Quantitative real-time polymerase chain reactions were deployed to assay RNA samples of spikes and seedlings $72 \mathrm{~h}$ after inoculation with a wild-type Fusarium asiaticum strain (5035) and a Tri5- strain or $24 \mathrm{~h}$ after treatment with deoxynivalenol (DON). Transcript amounts relative to mock and their standard error values are derived from Figures 2 to 5 .

${ }^{\mathrm{b}}$ Strains 5035 and Tri5-, $72 \mathrm{~h}$ after inoculation; DON, $24 \mathrm{~h}$ after treatment.

c * and $* *$ indicate significance at $P<0.05$ and 0.01 , respectively.

${ }^{\mathrm{d}}$ Phenotype: R, resistant; S, susceptible.
} 
molecular analyses of interaction between wheat and Fusarium pathogens. Coleoptile inoculation used here was carried out under strictly controlled conditions and, hence, showed a good reproducibility for different wheat cultivars and strains in different years and laboratories (37).

This study revealed that a quantitative nature of resistance reaction to a nonspecific fungal pathogen displayed a resistance inversion between seedlings and spikes in wheat, which was closely associated with the expression of a plant cytochrome P450 gene. This association was further corroborated by a differential induction of the P450 gene by the fungal mycotoxin. The resistance-dependent expression patterns imply that FHB resistance and FSB resistance may share common signal transduction pathways for the activation of the defense genes such as the cytochrome gene. These results may serve as a foundation for dissecting mechanisms and regulations underlying FHB and FSB resistance reactions in wheat and revealing functions of the plant cytochrome $\mathrm{P} 450$ gene in detoxification and defense.

\section{ACKNOWLEDGMENTS}

This work was supported by the National Basic Research Program of China (2009CB118806), the National Natural Science Foundation of China (30530510, 30571160, 30771337), and the Ministry of Science and Technology of China (2007AA10Z425).

\section{LITERATURE CITED}

1. Ansari, K. I., Walter, S., Brennan, J. M., Lemmens, M., Kessans, S., McGahern, A., Egan, D., and Doohan, F. M. 2007. Retrotransposon and gene activation in wheat in response to mycotoxigenic and nonmycotoxigenic-associated Fusarium stress. Theor. Appl. Genet. 114:927937.

2. Barcellos, A. L., Roelfs, P., and Moraes-Fernandes, M. I. B. 2000. Inheritance of adult plant leaf rust resistance in the Brazilian wheat cultivar Toropi. Plant Dis. 84:90-93.

3. Buerstmayr, H., Ban, T., and Anderson, J. A. 2009. QTL mapping and marker-assisted selection for Fusarium head blight resistance in wheat: A review. Plant Breed. 128:1-26.

4. Chen, L. F., Bai, G. H., and Desjardins, A. E. 2000. Recent Advances in Wheat Head Scab Research in China. U.S. Dep. Agric. Agric. Res. Serv. National Agricultural Library, Beltsville, MD.

5. Desjardins, A. E., Proctor, R. H., Bai, G. H., McCormick, S. P., Shaner, G., Buechley, G., and Hohn, T. M. 1996. Reduced virulence of trichothecene-nonproducing mutants of Gibberella zeae in wheat field tests. Mol. Plant-Microbe Interact. 9:775-781.

6. Desmond, O. J., Edgar, C. I., Manners, J. M., Maclean, D. J., Schenk, P. M., and Kazan, K. 2005. Methyl jasmonate induced gene expression in wheat delays symptom development by the crown rot pathogen Fusarium pseudograminearum. Physiol. Mol. Plant Pathol. 67:171-179.

7. Duvick, J. P., Rood, T., Gururaj R, A., and Marshak, D. R. 1992. Purification and characterization of a novel antimicrobial peptide from maize (Zea mays L.) kernels. Biol. Chem. 267:18814-18820.

8. Frohberg, R. C., Stack, R. W., and Mergoum, M. 2004. Registration of spring wheat germplasm ND2710 resistant to Fusarium head blight. Crop Sci. 44:1498-1499.

9. Howe, G. A., and Schilmiller, A. L. 2002. Oxylipin metabolism in response to stress. Curr. Opin. Plant Biol. 5:230-236.

10. Kandel, S., Morant, M., Benveniste, I., Blee, E., Werck-Reichhart, D., and Pinot, F. 2005. Cloning, functional expression, and characterization of CYP709C1, the first sub-terminal hydroxylase of long chain fatty acid in plants: Induction by chemicals and methyl jasmonate. J. Biol. Chem. 280:35881-35889.

11. Kong, L., Anderson, J. M., and Ohm, H. W. 2005. Induction of wheat defense and stress-related genes in response to Fusarium graminearum. Genome 48:29-40.

12. Liu, S., Griffey, C. A., and Saghai Maroof, M. A. 2001. Identification of molecular markers associated with adult plant resistance to powdery mildew in common wheat cultivar Massey. Crop Sci. 41:1268-1275.

13. Livak, K. J., and Schmittgen, T. D. 2001. Analysis of relative gene expression data using real-time quantitative PCR and the 2 (-Delta Delta C (T)) Method. Methods 25:402-408.

14. McFadden, J. J., Gronwald, J. W., and Eberlein, C. V. 1990. In vitro hydroxylation of bentazon by microsomes from naphthalic anhydridetreated corn shoots. Biochem. Biophys. Res. Commun. 168:206-213.

15. McMullen, M., Jones, R., and Gallenberg, D. 1997. Scab of wheat and barley: A re-emerging disease of devastating impact. Plant Dis. 81:13401348.

16. Mew, T. W., Cruz, C. M. V., and Reyes, R. C. 1981. Characterization of resistance in rice to bacterial blight. Ann. Phytopathol. Soc. Jpn. 47:5867.

17. Miller, G. P., Jones, D. R., Sullivan, S. Z., Mazur, A., Owen, S. N., Mitchell, N. C., Radominska-Pandya, A., and Moran, J. H. 2009. Assessing cytochrome P450 and UDP-glucuronosyltransferase contributions to warfarin metabolism in humans. Chem. Res. Toxicol. 22:1239-1245.

18. Morant, M., Bak, S., Moller, B. L., and Werck-Reichhart, D. 2003. Plant cytochromes P450: Tools for pharmacology, plant protection and phytoremediation. Curr. Opin. Biotechnol. 14:151-162.

19. Noordermeer, M. A., Veldink, G. A., and Vliegenthart, J. F. 2001. Fatty acid hydroperoxide lyase: a plant cytochrome p450 enzyme involved in wound healing and pest resistance. Chembiochem 2:494-504.

20. Page, V., and Schwitzguebel, J. P. 2009. The role of cytochromes P450 and peroxidases in the detoxification of sulphonated anthraquinones by rhubarb and common sorrel plants cultivated under hydroponic conditions. Environ. Sci. Pollut. Res. Int. 16:805-816.

21. Parry, D. W., Jenkinson, P., and McLeod, L. 1995. Fusarium ear blight (scab) in small grain cereals-a review. Plant Pathol. 44:207-238.

22. Pritsch, C., Vance, C. P., Bushnell, W. R., Somers, D. A., Hohn, T. M., and Muehlbauer, G. J. 2001. Systemic expression of defense response genes in wheat spikes as a response to Fusarium graminearum infection. Physiol. Mol. Plant Pathol. 58:1-12.

23. Qu, B., Li, H. P., Zhang, J. B., Xu, Y. B., Huang, T., Wu, A. B., Zhao, C. S., Carter, J., Nicholson, P., and Liao, Y. C. 2008. Geographic distribution and genetic diversity of Fusarium graminearum and F. asiaticum on wheat spikes throughout China. Plant Pathol. 57:15-24.

24. Ralston, L., Kwon, S. T., Schoenbeck, M., Ralston, J., Schenk, D. J., Coates, R. M., and Chappell, J. 2001. Cloning, heterologous expression, and functional characterization of 5-epi-aristolochene-1,3-dihydroxylase from tobacco (Nicotiana tabacum). Arch. Biochem. Biophys. 393:222235.

25. Ruckenbauer, P., Buerstmayr, H., and Lemmens, M. 2001. Present strategies in resistance breeding against scab (Fusarium spp.). Euphytica 119:121-127.

26. Sambrook, J., Fritsch, E. F., and Maniatis, T. 1989. Bacterial media, Antibiotics, and Bacterial Strains. Page 908 in: Molecular Cloning: A Laboratory Manual, 2nd ed. Cold Spring Harbor Laboratory, Cold Spring Harbor, NY.

27. Seyfarth, R., Feuillet, C., Schachermayr, G., Winzeler, M., and Keller, B. 1999. Development of a molecular marker for the adult plant leaf rust resistance gene Lr35 in wheat. Theor. Appl. Genet. 99:554-560.

28. Simpson, D. R., Thomsett, M. A., and Nicholson, P. 2004. Competitive interactions between Microdochium nivale var. majus, M. nivale var. nivale and Fusarium culmorum in planta and in vitro. Environ. Microbiol. 6:79-87.

29. Soulie, M. C., Perino, C., Piffeteau, A., Choquer, M., Malfatti, P., Cimerman, A., Kunz, C., Boccara, M., and Vidal-Cros, A. 2006. Botrytis cinerea virulence is drastically reduced after disruption of chitin synthase class III gene (Bcchs3a). Cell Microbiol. 8:1310-1321.

30. Stack, R. W. 2003. History of Fusarium head blight with emphasis on north America. Page 1-34 in: Fusarium Head Blight of Wheat and Barley. K. J. Leonard and, W. R. Bushnell, eds. American Phytopathological Society Press, St. Paul, MN

31. Tamburic-Ilincic, L., Somers, D., Fedak, G., and Schaafsma, A. 2009. Different quantitative trait loci for Fusarium resistance in wheat seedlings and adult stage in the Wuhan/Nyubai wheat population. Euphytica 165:453-458.

32. Tekauz, A., McCallum, B., and Gilbert, J. 2000. Review: Fusarium head blight of barley in western Canada. Can. J. Plant Pathol. 22:9-16.

33. Trognitz, F., Manosalva, P., Gysin, R., Niño-Liu, D., Simon, R., del Rossario Herrera, M., Trognitz, B., Ghislain, M., and Nelson, R. 2002. Plant defense genes associated with quantitative resistance to potato late blight in Solanum phureja $\times$ dihaploid $S$. tuberosum hybrids. Mol. PlantMicrobe Interact. 15:587-597.

34. Walter, S., Brennan, J. M., Arunachalam, C., Ansari, K. I., Hu, X. J., Khan, M. R., Trognitz, F., Trognitz, B., Leonard, G., Egan, D., and Doohan, F. M. 2008. Components of the gene network associated with genotype-dependent response of wheat to the Fusarium mycotoxin deoxynivalenol. Funct. Integr. Genomics 8:421-427.

35. Weber, H. 2002. Fatty acid-derived signals in plants. Trends. Plant Sci. 7:217-224.

36. Weber, H., Chetelat, A., Caldelari, D., and Farmer, E. E. 1999. Divinyl ether fatty acid synthesis in late blight-diseased potato leaves. Plant Cell 11:485-493.

37. Wu, A. B., Li, H. P., Zhao, C. S., and Liao, Y. C. 2005. Comparative pathogenicity of Fusarium graminearum isolates from China revealed by wheat coleoptile and floret inoculations. Mycopathologia 160:75-83. 
38. Xie, G. Q., Zhang, M. C., Magner, T., Ban, T., Chakraborty, S., and Liu, C. J. 2006. Evidence that resistance to Fusarium head blight and crown rot are controlled by different genes in wheat. Page 15-20 in: The Global Fusarium Initiative for International Collaboration. A Strategic Planning Workshop. CIMMYT, El Batán, Mexico.

39. Xu, X. M., Parry, D. W., Nicholson, P., Thomsett, M. A., Simpson, D., Edwards, S. G., Cooke, B. M., Doohan, F. M., Brennan, J. M., and Moretti, A. 2005. Predominance and association of pathogenic fungi causing Fusarium ear blight in wheat in four European countries. Eur. J. Plant Pathol. 112:143-154.

40. Yang, Z. J., and Ren, Z. L. 2001. Chromosomal distribution and genetic expression of Lophopyrum elongatum (Host) A. Love genes for adult plant resistance to stripe rust in wheat background. Genet. Resour. Crop Evol. 48:183-187.

41. Zhang, J. B., Li, H. P., Dang, F. J., Qu, B., Xu, Y. B., Zhao, C. S., and Liao, Y. C. 2007. Determination of the trichothecene mycotoxin chemotypes and associated geographical distribution and phylogenetic species of the Fusarium graminearum clade from China. Mycol. Res. 111:967-975.

42. Zhou, W., Kolb, F. L., and Riechers, D. E. 2005. Identification of proteins induced or upregulated by Fusarium head blight infection in the spikes of hexaploid wheat (Triticum aestivum). Genome 48:770-780.

43. Zimmerlin, A., and Durst, F. 1992. Aryl hydroxylation of the herbicide diclofop by a wheat cytochrome P-450 monooxygenase: Substrate specificity and physiological activity. Plant Physiol. 100:874-881. 